\title{
HAHN, Peter Michael, LORENZ, Hellmut, Pracht und Herrlichkeit. Adlig-fürstliche Lebensstile im 17. und 18. Jahrhundert
}

\section{Christophe Duhamelle}

\section{(2) OpenEdition}

\section{Journals}

Édition électronique

URL : http://journals.openedition.org/ifha/1397

DOI : 10.4000/ifha.1397

ISSN : 2198-8943

\section{Éditeur}

IFRA - Institut franco-allemand (sciences historiques et sociales)

Référence électronique

Christophe Duhamelle, «HAHN, Peter Michael, LORENZ, Hellmut, Pracht und Herrlichkeit. Adlig-fürstliche Lebensstile im 17. und 18. Jahrhundert », Revue de l'IFHA [En ligne], Date de recension, mis en ligne le 01 janvier 1999, consulté le 22 septembre 2020. URL : http://journals.openedition.org/ifha/1397 ; DOI : https://doi.org/10.4000/ifha.1397

Ce document a été généré automatiquement le 22 septembre 2020.

(C)IFHA 


\title{
HAHN, Peter Michael, LORENZ, Hellmut, Pracht und Herrlichkeit. Adlig-fürstliche Lebensstile im 17. und 18. Jahrhundert
}

\author{
Christophe Duhamelle
}

Ce recueil se fixe pour objectif d'étudier les résidences princières et nobiliaires non plus seulement sous l'angle d'une histoire des formes architecturales, mais également sous celui des perceptions et représentations que les aristocrates se faisaient de leurs constructions. Ce dessein est poursuivi dans deux directions. La première réside dans l'analyse de récits ou de notes de voyage rédigés par des princes polonais et saxons parcourant l'Europe au XVIIe s. (P.M. HAHN) ou par la comtesse de Lynar et son fils rendant visite dans les années 1770 à des parents et amis du Brandebourg (V. CZECH). Les appréciations sur la nouveauté et les qualités esthétiques d'un bâtiment n'y jouent pas un rôle primordial. En revanche, les rituels et les espaces de l'accueil et du raccompagnement, la richesse des matériaux et du mobilier, la commodité des chasses, les souvenirs dynastiques et, de plus en plus, les charmes champêtres de la nature environnante, focalisent un intérêt d'»utilisateurs « experts en sociabilité aristocratique et en distinctions sociales. L'autre direction d'étude, plus classique, lie l'analyse des constructions à celle des statuts. Rappelant la position ambiguë, de 1692 à 1788 , des margraves de Schwedt - branche cadette victime de l'instauration de la primogéniture pour toutes les possessions des Electeurs de Brandebourg - U. GEISELER montre leur volonté de contruire tout de même une petite résidence de rang princier, malgré l'opposition croissante que suscite cette entreprise à la cour de Berlin. E. RUST voit en la chapelle (octogonale et à tribunes) des Alvensleben à Hundisburg (1693-97) un élément précis de statut et de réseau nobiliaire autant qu'une réalisation précoce des théories de L.C. Sturm sur une architecture spécifiquement protestante. La magnificence du chateau des Promnitz à Sorau en Lusace (S. KIESANT) reflète enfin la réussite d'un ministre qui, ayant épousé une princesse de Saxe-Weissenfels, cherche à s'approcher du modèle de la résidence princière. Illustré de textes et de gravures, ce 
recueil offre donc des aperçus éclairants et précis sur un sujet qui mérite mieux qu'un traitement trop souvent anecdotique.

2 Christophe DUHAMELLE 